$57 \mid 2016$

Innovations pédagogiques dans l'enseignement des langues étrangères : perspective historique (XVle-XXle siècles)

\title{
Denise BOUCHE (1925-2016)
}

\section{Gérard Vigner}

\section{(2) OpenEdition}

\section{Journals}

Electronic version

URL: https://journals.openedition.org/dhfles/4434

DOI: $10.4000 /$ dhfles.4434

ISSN: 2221-4038

\section{Publisher}

Société Internationale pour l'Histoire du Français Langue Étrangère ou Seconde

Printed version

Date of publication: 1 December 2016

Number of pages: 179-181

ISSN: 0992-7654

\section{Electronic reference}

Gérard Vigner, "Denise BOUCHE (1925-2016)", Documents pour l'histoire du français langue étrangère ou seconde [Online], 57 | 2016, Online since 01 February 2018, connection on 25 March 2023. URL: http:// journals.openedition.org/dhfles/4434 ; DOI: https://doi.org/10.4000/dhfles.4434

This text was automatically generated on 25 March 2023.

All rights reserved 


\title{
Denise BOUCHE (1925-2016)
}

\author{
Gérard Vigner
}

1 Dès sa création en décembre 1987, la Sihfles va compter parmi ses adhérents les plus actifs, Denise Bouche, professeur d'histoire contemporaine à l'université de Nancy 2. Née en 1925, ancienne élève de l'Ecole normale supérieure de Sèvres, agrégée d'histoire, Denise Bouche, après avoir enseigné à Dakar en début de carrière, entre à l'université de Nancy 2 en 1968, où elle exercera jusqu'à son départ à la retraite.

2 Après avoir soutenu sa thèse de $3 \mathrm{e}$ cycle en 1965, publiée sous le titre Les villages de liberté en Afrique noire française, 1887-1910, Paris-La Haye, Mouton, 1968, elle soutient sa thèse d'Etat, en 1974 auprès de l'université de Paris I, sur le thème : L'enseignement dans les territoires français de l'Afrique occidentale de 1817 à 1920 : mission civilisatrice ou formation d'une élite? ( Atelier Reproduction des thèses, Université Lille III, 1975), deux forts volumes de 947 pages en tout.

Denise Bouche va en effet se consacrer à l'histoire de la colonisation et cela, à un moment où les travaux portant sur cette période sont encore peu nombreux. En effet, dans la suite des indépendances des pays colonisés, devenus à ce moment-là pays du Tiers-Monde, les temps sont plus à une condamnation sans examen de cette période, qu'à une analyse attentive de son histoire, sur la base d'une consultation méthodologiquement assurée des archives. Denise Bouche fait en effet partie de cette première génération de chercheurs qui dans le début des années 70 soutiennent des thèses d'Etat, avec Catherine Coquery-Vidovitch ou Yves Person (mais en signalant encore la thèse de $3 e$ cycle de Fanny Colonna sur les instituteurs algériens ${ }^{1}$ qui inaugure un champ de recherche consacré aux enseignants indigènes). Chercheurs aux sensibilités politiques très variées, mais qui, sur un sujet encore hautement inflammable, la fin de la guerre d'Algérie n'est pas très loin, ont su porter le regard du spécialiste, doté d'une méthodologie de recherche rigoureusement construite.

Denise Bouche va ainsi faire ressortir la complexité des situations, la diversité des acteurs, comme des intérêts qui les lient, ainsi que les hésitations de politiques engagées depuis une métropole dont les objectifs en la matière sont loin d'être clairs et cohérents. Sa parfaite connaissance du personnel politique français de l'époque lui permet de rendre compte avec toute la précision nécessaire de choix dont la cohérence 
ne constitue pas la qualité la plus évidente. De la même manière, elle analyse avec toute l'acuité nécessaire la mise en œuvre hésitante des politiques de scolarisation dans les territoires des colonies. Elle sait rendre compte des multiples conflits qui sur place purent opposer commandants de cercles et enseignants, administrateurs et chefs de service. Elle ne manqua pas d'évoquer à de nombreuses reprises le débat qui opposa, à l'intérieur de l'administration coloniale, partisans de l'assimilation et partisans d'un enseignement adapté. Son article «Dans quelle mesure Paris a-t-il voulu diriger l'enseignement colonial?", publié dans Documents pour l'histoire du français langue étrangère ou seconde $(25,2000)$, constitue de ce point de vue là une utile mise au point. Elle s'intéressera encore, mais d'une moindre manière, à l'action des missions chrétiennes, ainsi qu'à celle des militaires, premiers acteurs de l'enseignement dans les territoires nouvellement conquis avec les écoles de poste. Une de ses premières contributions intitulée "Les écoles françaises au Soudan à l'époque de la conquête. 1884-1900 » est publiée dans les Cahiers d'études africaines $(22,1966)$.

5 Elle va consacrer l'essentiel de ses travaux à l'Afrique de l'ouest et notamment au Sénégal, sans en faire cependant un champ de recherche exclusif, portant tout à la fois sur les questions de politique coloniale et d'enseignement, dans l'éclairage de sa thèse d'Etat.

Denise Bouche publie en 1991, chez Fayard, le tome 2 de l'Histoire de la colonisation française. Flux et reflux (1815-1962), 607 p., ouvrage de synthèse qui couvre la période correspondant à ce que les historiens appellent « la deuxième colonisation », c'est-àdire la période qui voit la France reconstruire progressivement un autre empire colonial, après la quasi- disparition du premier au terme du traité de Paris du 30 mai 1814, jusqu'à la phase de liquidation qui se situe quelque part entre 1954 et 1962.

7 Ses interventions à la Sihfles s'inscriront dans cette orientation et permettront de mettre l'accent sur un autre vecteur de diffusion du français, celui de l'école indigène dans les colonies, longtemps négligé, alors qu'il fut à l'origine de ce que l'on nomme aujourd'hui les francophonies du sud, en parfaite connaisseuse des différents appareils institutionnels qui se construisirent au fur et à mesure du développement de l'entreprise coloniale, ainsi que des personnels politiques et administratifs associés

8 Depuis, les travaux sur l'enseignement dans l'empire colonial français se sont multipliés, ce dont on ne peut que féliciter, mais on lui saura gré d'avoir de la sorte avoir ouvert la route aux nombreux chercheurs qui depuis explorent ce domaine.

\section{NOTES}

1. On doit tenir compte aussi des travaux pionniers en France de chercheurs tels Charles-André Julien ou Charles-Robert Ageron qui dès les années 50 commencent à publier sur l'histoire de la colonisation en Afrique du nord. 


\section{AUTHOR}

GÉRARD VIGNER

SIHFLES 